\title{
O Problema Habitacional na América Latina: Exemplos do Brasil e Chile
}

\section{The Housing Problem in Latin America: Examples from Brazil and Chile}

\author{
Graziela Rossatto Rubin \\ Mestranda do Programa de Pós Graduação em Geografia e Geociências da Universidade Federal de Santa Maria \\ (PPGGEO - UFSM) \\ grazirrubin@gmail.com
}

RESUMO: O presente artigo faz um resgate histórico da problemática habitacional na América Latina e traz como exemplos o Brasil e o Chile, países que apresentaram políticas interessantes para tentar resolver o problema da habitação. A partir do século XIX, com a industrialização e, consequentemente,o aumento da urbanização, as cidades da América Latina passaram a sofrer com os problemas urbanos. Entre eles, a questão habitacional se destaca por ser um problema que afeta nossas cidades até os dias de hoje.

Palavras chave: Problema Habitacional; Política Habitacional; Déficit Habitacional; Urbanização

Abstract: This article make a historical rescue about the housing problem in Latin America and bring to example the Brazil and Chile, countries that have interesting polity to try to solve the housing problem. From the XIX century, with the industrialization and, consequently, the increasing urbanization, the Latin America cities had suffered with the urban problems. Including, the housing question stands out because is a problem that affect our cities until today.

Keywords: Housing Problem; Housing Policy; Housing Deficit; Urbanization

\section{Introdução}

O problema habitacional é presente em todos os países latinoamericanos e muitos são os projetos para tentar amenizar o déficit habitacional e a falta de moradia digna da população de baixa renda. Assim, o presente artigo tratará desse problema nos países da América Latina.

Para isso, será realizado um referencial teórico buscando mostrar a real situação que esses países, inclusive o Brasil, têm enfrentado para tratar do problema habitacional e as diferentes maneiras encontradas para sua resolução.

Ao analisar os projetos e as intervenções realizadas, percebeu-se que o Chile possui um histórico na tratativa habitacional muito interessante e, muitas vezes, similar ao histórico habitacional brasileiro. Além disso, o modelo chileno serviu de inspiração para muitos outros países, por sua aceitação e eficiência. Assim, o artigo apresentará, primeiramente, as ações realizadas em toda a América Latina e depois fará uma abordagem dos casos brasileiros e chileno. 
Finalmente, o artigo tentará fazer um comparativo e ver melhorias que podem ser feitas na política habitacional brasileira para que esta se consolide cada vez mais e consiga diminuir ao máximo o déficit habitacional.

\section{O Problema Habitacional na América Latina}

Com a industrialização eo aumento da urbanização, Serrano (2002, P. 62) coloca que "La población latinoamericana ha optado obcecadamente por assentarse en áreas urbanas, donde, como ya se h aapuntado, habitan hoy 360 millones de personas".

Em 1970, a população urbana representava aproximadamente 57\% da população total, em 1999, atingiu $73 \%$ e a estimativa é de que em 2025 a população urbana atinja $85 \%$ da população total nos países latinoamericanos (Serrano, 2002).

Assim, a partir do século XX, nos países em desenvolvimento, percebe-se uma intervenção significativa do Estado na questão habitacional. A atuação do Estado mostra diferentes níveis de intervenção do setor privado, da sociedade civil e dos beneficiados dos programas habitacionais (Ramírez, 2002).

Nos países da América Latina, as políticas habitacionais surgiram em meio ao processo de modernização e acelerada urbanização ocorridos. As políticas eram destinadas à diminuição da pobreza e assim, foram construídas grandes obras públicas, distantes da área central urbana, na periferia da cidade. Essas políticas removeram favelas e assentamentos irregulares de áreas centrais, com infraestrutura, e acabaram por estimular a especulação imobiliária.

As experiências e interações internacionais foram importantes para a definição de políticas públicas como a habitacional e também a erradicação da pobreza. E, na tentativa de resolver o problema habitacional existente nos países da América Latina, foram construídas habitações baseadas em ideias propostas na Europa. Porém, ao se fazer isso, não se levou em consideração as necessidades da população local e uma nova realidade foi imposta para a população necessitada de habitações. Ou seja, as moradias eram, em geral, caras e inacessíveis aos pobres, fazendo com que estes permanecessem na periferia ou em assentamentos irregulares (Ramírez, 2002).

Segundo Serrano (2002, p. 64), "El déficit habitacional, cuantitativo y cualitativo, afecta a más de la mitad de los hogares latinoamericanos. Para absorberlo seria necesario 
construir o mejorar 53,6 millones de unidades". Além disso, muitas habitações não possuem infraestrutura mínima adequada, como rede de abastecimento de água e coleta de esgoto, além de serviços e equipamentos públicos e diretrizes para um planejamento urbano mais justo e coerente. A carência em infraestrutura agrava a situação e a vida nas cidades.

Como exemplo de políticas adotadas em países da América Latina, o Chile iniciou em 1985, uma política de financiamento habitacional onde o Estado subsidia e o setor privado executa. Esta política passou a ser exemplo entre os países latinoamericanos. A política consistiu em três pilares: economia, subsídio e crédito e teve êxitos notáveis, podendo ser considerado o único país da América Latina a conseguir diminuir seu déficit habitacional (Serrano, 2002).

Alguns países como Equador, Guatemala, Colômbia, Honduras e Venezuela se basearam na política habitacional implantada no Chile para tentar resolver o problema da moradia em seus países. Porém, em países com menor renda, administrações públicas menos dotadas que o Chile, o resultado não foi tão satisfatório.

Ao longo dos anos de 1980 e 1990, os investimentos destinados à habitação, na América Latina, tem sido inferiores aos investimentos em outras áreas sociais. Isso porque os gastos sociais geram um aumento na carga tributária, nos impostos territoriais e há uma resistência política muito grande para que isso não ocorra. Assim, torna-se tão necessário explorar novas fontes de financiamento para os programas habitacionais.

A construção da moradia não é o único problema encontrado nas cidades da América Latina, ou seja, a falta de terra urbanizada e o fornecimento de serviços e equipamentos básicos também afetam a vida da população de baixa renda. Assim, vemos no Brasil a criação do Estatuto da Cidade e na Bolívia a "OperacionNuevo Usme enColombia”, instrumentos importantes na tentativa de amenizar os problemas habitacionais existentes nas cidades.

Segundo Fernandes (2008)

Hay en Latinoamerica una gran diversidad de procesos informales que corresponden no solo a las diferentes situaciones registradas dentro de cada ciudad o incluso de cada asentamiento informal, sino tambien una profunda heterogeneidad de situaciones de tenencia de la tierra identificadas en cada pais. Las mas comunes son seguramente las ocupaciones informales de areas publicas y privadas, sea en favelas, villas, barriadas u otras formas de ocupacion irregular, sea mediante la compra de lotes y/o de casas en parcelaciones "clandestinas", "piratas" e "irregulares" (FERNANDES, 2008, p. 26).

Geo UERJ - Ano 15, no. 24, v. 1, $1^{\circ}$ semestre de 2013 p. 125-144

ISSN: 1415-7543E-ISSN: 1981-9021

http://www.e-publicacoes.uerj.br/index.php/geouerj 
Os assentamentos informais geram exclusão e segregação social. A população, geralmente, mora em áreas impróprias ou com algum risco e não possui acesso ao crédito formal a terra e a moradia.

Segundo Fernandes (2008)

\begin{abstract}
es necesario senalar que programas deregularizacion tienen una naturaleza esencialmente curativa. Ellos se plantean como respuesta a realidades constituidas a lo largo del tiempo, situaciones consolidadas, en las cuales muchas veces tambien derechos se constituyeron. Dichos programas solo tienen sentido y eficacia si concebidos en el contexto de un conjunto mas amplio de politicas publicas preventivas, que rompan el circulo vicioso - y viciado - que, a lo largo de decadas, produjo ciudades por la via de la informalidad (FERNANDES, 2008, p. 31).
\end{abstract}

Os programas de regularização de assentamentos informais e provisão de novas moradias ainda são insuficientes e insatisfatórios. A maioria dos países latinoamericanos iniciou suas experiências nos anos de 1980, porém no Peru e no México, leis específicas para a melhoria da situação dos assentamentos informais foram adotadas já entre os anos de 1960 e 1970 (Fernandes, 2008).

Além disso, Fernandes (2008, p. 34) destaca que "Por lo general, las politicas de regularizacion son especificas, no llevando en cuenta el caracter estructural y estructurador de los procesos de produccion informal del espacio urbano".

Quando se fala em déficit habitacional nos países latinoamericanos, a realidade existente é um grande número de imóveis vazios nas áreas urbanas, entre propriedades públicas e privadas. Porém, esses imóveis muito pouco se utilizam com função social, para políticas habitacionais e de regularização fundiária. Isso ocorre muito devido à especulação imobiliária, e aos poucos, geram-se imensas áreas centrais sem qualquer construção e, as habitações sociais são construídas em áreas distantes, desprovidas de qualquer tipo de infraestrutura.

Também se pode destacar que essas moradias, com alto custo para a população carente, passaram a abrigar funcionários públicos, militares, comerciantes, ou seja, uma população com renda suficiente para arcar com as despesas dessas habitações.

Os programas e políticas de habitação de interesse social e regularização fundiária tem como principal objetivo garantir habitação e acesso à terra a população necessitada. Algumas organizações internacionais como o Programa das Nações Unidas para os Assentamentos Humanos (UN - HABITAT), o Banco Mundial e bancos regionais de desenvolvimento estão 
auxiliando na promoção de ações para melhoria dessa situação, que se prolonga durante anos nos países da América Latina e em muitos outros países em desenvolvimento.

O Banco Mundial é um grande agente financeiro que busca o melhoramento das condições de habitação da população mais carente e, entre suas atuais prioridades está a dotação de infraestrutura básica para os que não a possuem. Desse modo, para que a situação habitacional da América Latina seja amenizada, é necessário ampliar, equipar e reparar as habitações em estado crítico (Serrano, 2002).

Além disso, o Banco também tem como prioridade tornar a habitação mais barata, com possibilidades de financiamentos acessíveis a toda a população. Porém, boa parte da população carente da América Latina encontra-se fora do mercado formal de habitações e a ideia ainda parece utópica (Serrano, 2002).

Segundo Posner (2012),

According to World Bank statistics, 128 million Latin Americans live in slums and the region needs no fewer than 28 million housing units to relieve the problems of crowded and substandard housing (Jha, 2007: 1). While the magnitude of the problem varies significantly between higher- and lowerincome countries in the region, it is substantial in both. 'In higher-income countries such as Argentina, Uruguay, Chile, Brazil and Mexico, one-third of the households live in inadequate conditions ... in low-income countries such as Bolivia and Guatemala, more than half of the households live in poor housing conditions' (Rojas, 2006: 3). International development institutions such as the World Bank, the Inter-American Development Bank (IADB) and the United States Agency for International Development (USAID) have been touting targeted assistance policies to address this enormous problem since the early 1980s (POSNER, 2012, p.51).

O Brasil e o Chile possuem modelos e propostas para tratar da questão habitacional muito similares, assim, serão analisados mais a fundo.

\section{O ProblemaHabitacional noBrasil}

A questão habitacional tornou-se problema com o aumento da urbanização brasileira. Isso ocorreu devido à migração das pessoas do campo para a cidade, a industrialização e a necessidade de habitações por essa população.

Para Maricato (2000, p.21), "O processo de urbanização recria o atraso apartir de novas formas, como contraponto à dinâmica de modernização". Ou seja, com o aumento da urbanização, aumentou a população urbana e, consequentemente, a necessidade de infraestrutura básica como saneamento, transporte, equipamentos públicos comunitários, entre

Geo UERJ - Ano 15, no. 24, v. 1, $1^{\circ}$ semestre de 2013 p. 125-144

ISSN: 1415-7543E-ISSN: 1981-9021

http://www.e-publicacoes.uerj.br/index.php/geouerj 
outros. Também aumentam outros problemas como a poluição do meio ambiente, violência, congestionamentos, invasões, habitações irregulares.

O acelerado processo de urbanização gerou necessidades e, mesmo que essas não tenham sido satisfatórias, "o território foi ocupado e foram geradas condições para viver nesse espaço" (MARICATO, 2000, p. 21).

Desde o período colonial o Brasil já apresentava cidades de grande porte, mas somente entre o final do século XIX e início do século XX é que a urbanização brasileira se consolida através da Proclamação da República, pela industrialização e pelo aumento do trabalhador livre.

Para Gomes; Silva; Silva (2003),

Nesse cenário é que o processo de urbanização foi desencadeado no Brasil, passando as cidades brasileiras, especialmente as grandes e médias, a requisitarem uma série de serviços e equipamentos que se colocavam na pauta de reivindicação da população, a qual deixava o campo para morar na cidade. Nesse momento já estava presente a questão do déficit de moradia (GOMES; SILVA; SILVA, 2003, p. 2).

A industrialização que se afirma a partir de 1930 e prolonga-se até o final da Segunda Guerra Mundial traz um avanço na economia brasileira, com o "fortalecimento do mercado interno, com grande desenvolvimento das forças produtivas, diversificação, assalariamento crescentee modernização da sociedade" (MARICATO, 2000, p.22).

$\mathrm{Na}$ década de 1930, o Estado é obrigado a tomar medidas mais palpáveis quanto à problemática habitacional. Assim, os Institutos de Aposentadoria e Pensões (IAPs) são autorizados a criarem carteiras prediais, reduzindo taxas de juros e ampliando prazos de pagamentos.

Em 1946 foi criada a Fundação da Casa Popular (FCP), "primeiro órgão de âmbito nacional, voltado exclusivamente para a provisão, mediante venda, de casas para a população de baixa renda" (PEQUENO, 2008, p.3). Primeiramente, funcionava com recursos provindos de impostos juntamente com a redistribuição de riqueza.

Na década de 1960, o país passa a produzir bens duráveis e bens de produção, dando à industrialização brasileira uma nova cara. Também se tornam mais necessários, nesses anos, instrumentos de planejamento e gestão, para a articulação do crescimento urbano, a provisão de infraestrutura, estruturação do sistema viário, controle do uso do solo.Até os anos de 1960, 
o Brasil não possuía uma política urbana nacional, apenas políticas específicas para determinadas áreas.

Para Pequeno (2008),

Todo este período coincide com a fase da história brasileira em que a industrialização passou a despontar como atividade econômica diretamente associada ao desenvolvimento. Grandes contingentes populacionais foram atraídos para os grandes centros urbanos, dinamizando o setor terciário, revertendo na provisão de infra-estruturas demandadas, gerando uma atmosfera de progresso, ainda que territorialmente concentrado (PEQUENO, 2008, p. 3).

Com o início da Ditadura Militar no Brasil, em 1964, o problema habitacional, através da formação do Sistema Financeiro de Habitação (SFH), passa a ser tratado de forma centralizada. O SFH era responsável pelos recursos do Fundo de Garantia por Tempo de Serviço (FGTS) e do Banco Nacional de Habitação (BNH). O BNH era "responsável pela formulação, gestão e execução da política nacional, contando com as Companhias de Habitação (COHABs) na execução de programas para as camadas de baixa renda" (PEQUENO, 2008, p.3).

Desse modo, vemos nas cidades brasileiras uma política destinada a mudar seu padrão de produção. Os recursos financeiros são dirigidos à produção habitacional de modo a modificar o perfil das grandes cidades, devido à verticalização com a construção dos edifícios de apartamentos. O SFH é o responsável pela explosão imobiliária consolidada pelos edifícios de apartamentos.

A política habitacional implementada pelo $\mathrm{BNH}$ esteve voltada, em seus primeiros anos, na população de baixa renda. Porém, aos poucos as classes menos favorecidas vão sendo deixadas de lado e o Banco passa então a atender a classe média.

Para Gomes, Silva; Silva (2003),

[...] o BNH foi um dos importantes promotores das transformações urbanas no Brasil. O Sistema Financeiro de Habitação - SFH -, gerenciado pelo $\mathrm{BNH}$, foi de fato um instrumento oficial através do qual se estabeleceram as condições para a capitalização das empresas ligadas à construção civil, além de permitir a estruturação de uma rede de agentes financeiros privados, realizando, assim, o financiamento da produção (GOMES; SILVA; SILVA, 2003, p.4).

Desse modo, se faz importante entender os aspectos de implantação das políticas habitacionais e sua ocupação no solo urbano, já que refletem no processo de urbanização. A

Geo UERJ - Ano 15, no. 24, v. 1, $1^{\circ}$ semestre de 2013 p. 125-144

ISSN: 1415-7543E-ISSN: 1981-9021

http://www.e-publicacoes.uerj.br/index.php/geouerj 
política habitacional apresenta uma lógica para a ocupação do espaço e gera uma dinâmica espacial.

Para Maricato (2000),

Infelizmente o financiamento imobiliário não impulsionoua democratização do acesso à terra por meio da instituição da função social da propriedade. Essa era a propostada reforma urbana preconizada pelos arquitetos no Congresso do IAB, Instituto de Arquitetos do Brasil, de 1963. A atividade produtiva imobiliária não subjugou as atividades especulativas, como ocorreu nos países centrais do capitalismo. O mercado não se abriu para a maior parte da população que buscava moradia nas cidades. Eledeu absoluta prioridade às classes médias e altas (MARICATO, 2000, p. 23).

O que vemos é a população carente sendo colocada em áreas inadequadas para moradia e para o desenvolvimento urbano racional, gerando gastos desnecessários com a expansão de infraestrutura para essas novas áreas e os governos desviam sua atenção desse problema. E a população, muitas vezes, acaba construindo suas próprias moradias, em áreas irregulares ou mesmo invadidas. Essa maneira, encontrada pela população de baixa renda para adquirir a casa própria, nos mostra as diferentes formas de estruturação sócio-espacial.

Para Gomes; Silva; Silva (2003)

Podemos dizer, então, que o ato de morar tem um conteúdo político, social, econômico e, principalmente, espacial. No contexto dessa espacialidade, podemos observar características diversas da habitação e, por conseguinte, formas espaciais diferentes, concretizando uma produção diferenciada da cidade (GOMES; SILVA; SILVA; 2003, p.2).

A resolução do problema habitacional é de difícil solução, pois a terra tem um preço e nem todos tem condições de pagar por ela, sendo dominada pelos que possuem maior poder aquisitivo.

Entre os anos de 1940 a 1980, o Brasil apresentou um crescimento econômico acelerado, porém continuou apresentando forte desigualdade social e, com o declínio econômico nos anos de 1980 a 1990, a sociedade desigual aumentou a exclusão social.

Durante as décadas de 1970 a 1980os recursos do BNH ficam escassos, isso ocorre pela inadimplência dos mutuários do $\mathrm{BNH}$, já contemplados com sua casa própria, a redução dos recursos do FGTS e o aumento do desemprego.

Sobre os recursos do BNH, Valença; Bonates (2010)comenta

The system counted on 3 major sources of finance: first, the compulsory 'savings' deposited in the FGTS accounts (by employers in benefit of their employees), which was used by the BNH to finance social housing; second, the voluntary passbook savings accounts system, which was used by SBPE

Geo UERJ - Ano 15, no. 24, v. 1, $1^{\circ}$ semestre de 2013 p. 125-144

ISSN: 1415-7543E-ISSN: 1981-9021

http://www.e-publicacoes.uerj.br/index.php/geouerj 
institutions (banks, building societies, savings associations) to finance middle-class housing; and third, profits from the repayments of mortgages conceded (VALENÇA, BONATES, 2010, p. 166).

Com os recursos do FGTS, o Banco financiava, primeiramente, contratos de companhias habitacionais públicas, como as COHABs ou cooperativas habitacionais, para a construção de habitações novas. Além disso, também financiava a hipoteca de habitações novas já prontas. Durante os anos de atuação do Banco, foram poucos os casos de financiamentos de habitação de segunda mão ou para arrendamento.

O SFH construiu em torno de 2,4 milhões de moradias entre os anos de 1964 a 1986 (Maricato, 2000). Porém, esse número poderia ter sido maior se não houvesse tanto desperdício, existissem políticas urbanas mais racionais e que privilegiassem a maioria da população.

Resultado da crise econômica da década de 1980, as fontes de financiamentos foram afetadas negativamente. $\mathrm{O}$ desemprego aumentou, a renda caiu, os trabalhadores retiraram seus fundos do FGTS e contas de poupança. Em 1984, há um aprofundamento da crise e o BNH tenta fazer uma compensação dos detentores de hipoteca pela perda de poder de compra (Valença; Bonates, 2010).

No início da Nova República (1985) a situação habitacional no Brasil apresentava "baixo desempenho social, alto nível de inadimplência, baixa liquidez do sistema, movimentos de mutuários organizados nacionalmente e grande expectativa de que as novas autoridades pudessem resolver a crise do sistema sem a penalização dos mutuários" (CARDOSO, 2007, p.15).

A reivindicação dos mutuários foi atendida e o primeiro ano da administração do presidente José Sarney (1985) foi marcado pelo "fim das mobilizações e dos movimentos regionais e nacionais de mutuários" (CARDOSO, 2007, p.15). Porém, ao conceder subsídio aos mutuários sem outra medida compensatória, agravou-se ainda mais o déficit do SFH.

O Governo do Presidente José Sarney adotou diversas medidas que indicavam profundas mudanças, discutia-se desde a descentralização do BNH até mudanças no sistema de financiamento. Dada a complexidade da questão e falta de consenso sobre a reforma, "o governo decretou extinção do Banco" (CARDOSO, 2007, p.16 apud MELO, 1990). Isso ocorreu devido a fragilidade encontrada diante das "flutuações macroeconômicas dos anos 80" (BOTEGA, 2007, p.69). Valença; Bonates (2010, p.166) complementa que "In November 
1986, in the midst of the second CruzadoPlan, the Sarney government decided to close the $\mathrm{BNH}$, the head of the system, which employed nearly 10,000 people”.

As atribuições do BNH foram incorporadas pela Caixa Econômica Federal (CEF) e foram definidas novas diretrizes para o gerenciamento dos programas. A política passou a ser fragmentada e as ações que eram implementadas perderam força com a redução orçamentária e, aos poucos, os governos estaduais foram retirando-se do setor habitacional levando à extinção das COHABs.

Para Gomes; Silva; Silva (2003)

Com a extinção do $\mathrm{BNH}$, o sistema habitacional brasileiro passou a vivenciar intensas crises, que resultaram num alto endividamento desse sistema, sem falar na incapacidade de implementação de novos projetos. As crises tiveram sua origem na inadimplência dos mutuários, tendo em vista $o$ aumento crescente das prestações, que não era acompanhado pela política salarial. Nesse contexto, houve uma paralisação na dinâmica da política habitacional, ficando esta limitada a secretarias e ministérios criados ao longo de vários governos (GOMES; SILVA; SILVA, 2003, p.6).

Iniciou-se uma nova etapa para as políticas urbana e habitacional brasileira, pois a desarticulação do BNH agravou os problemas existentes e a questão urbana e habitacional passou a depender de instituições onde esses assuntos não eram os objetivos principais. Também, por parte da Caixa Econômica, tornou-se difícil dinamizar programas alternativos para os setores de menor renda. Foi uma fase de constantes reformulações nos órgãos responsáveis pelas políticas habitacionais.

A sociedade brasileira, em 1988, passa a contar com um importante aliado, a Constituição de 1988 que trata do planejamento e gestão urbana especificamente nos artigos 182 e 183, estabelecendo a gestão da política urbana brasileira. Earle (2012, p.116) complement aque "The Constitution of 1988 has particular resonance for Brazilian society, marking the end of the military regime and, through its highly progressive content, setting out a legal framework for an egalitarian society".Mesmo com esse importante instrumento, não se garantiu uma justiça social efetiva nem uma gestão democrática para as cidades brasileiras.

Durante o início dos anos de 1990, no governo de Fernando Collor de Melo, a situação da política habitacional brasileira se agrava ainda mais, pois as Cadernetas de Poupança são confiscadas e ocorre uma estagnação na poupança e no FGTS. Além disso, o Estado passa a se ausentar da política habitacional. O governo Collor contou com os estados e municípios 
para a concessão de subsídios já que nenhuma outra ação foi tomada para promover a política em nível federal.

Foi proposta pelo governo a criação do Sistema Nacional de Habitação, com procedimentos inovadores e democráticos na questão habitacional, onde a população participaria na tomada de decisões. Entre as propostas, havia o incentivo na participação de estados e municípios para o incentivo de programas locais (Valença; Bonates, 2010).

Após o impeachment de Collor, assumiu a presidência Itamar Franco, num cenário onde o sistema de provisão de moradias encontrava-se em apuros, já que os recursos do FGTS estavam escassos e o país encontrava-se em recessão provocada pelo Plano Collor.

Durante os anos de 1990 a 1994, aproximadamente, quinhentas mil novas moradias foram construídas através de programas que contavam com recursos do FGTS. Os principais programas eram: Programa de Ação Imediata para Habitação (PAIH), PROHAP (Programa de Habitação Popular) e PEP (Programa Empresário Popular).

O governo criou, no final dos anos de 1990, o Programa Carta de Crédito, que tinha por objetivo proporcionar o financiamento de construções de maneira associativa, onde as pessoas eram agrupadas e organizadas para a construção de conjuntos habitacionais e condomínios fechados (Gomes; Silva; Silva, 2003).

A partir de 1995, no governo de Fernando Henrique Cardoso, uma nova postura adotada pelos municípios diante do problema habitacional serviu de referência nacional. Ocorre, então, a retomada nos financiamentos de habitação e saneamento com base nos recursos do FGTS. Novos referenciais como flexibilidade, descentralização e diversidade foram adotados, rejeitando programas convencionais que tinham como base a construção de grandes conjuntos habitacionais.

A Secretaria de Política Urbana, responsável pelo setor habitacional, em 1996, apresentou a Política Nacional de Habitação. Esse documento continha novos programas, onde o financiamento à produção não era um privilégio.

O governo de Fernando Henrique Cardoso (FHC) criou programas como o PróMoradia, voltado à urbanização de áreas precárias e em 1999, o Programa de Arrendamento Residencial (PAR) para a produção de novas unidades para arrendamento, utilizando recursos do FGTS e de origem fiscal. No PAR, o beneficiário se torna proprietário do imóvel apenas ao final do pagamento.

Geo UERJ - Ano 15, no. 24, v. 1, $1^{\circ}$ semestre de 2013 p. 125-144

ISSN: 1415-7543E-ISSN: 1981-9021

http://www.e-publicacoes.uerj.br/index.php/geouerj 
Após uma avaliação das necessidades de moradia no país e as fontes de financiamento existentes, estabeleceu-se um tempo de quinze anos para solucionar os problemas, garantindo acesso à moradia digna para todo cidadão brasileiro (Bonduki, 2008). Desse modo, o Projeto Moradia, concebido em 1999/2000, foi proposto para solucionar a questão habitacional no Brasil.

O governo FHC também criou o Programa de Subsídio de Habitação (PSH), que tinha por objetivo a construção de habitação de baixo custo para uma população com renda entre um e três salários mínimos (Valença, Bonates, 2010). Ou seja, o programa pretendia atender à população realmente necessitada, pois essa faixa de renda foi pouco atendida pelos programas habitacionais implantados até o momento.

Para Valença;Bonates (2010),

Generally speaking, the Cardoso government's housing policy proposals just like in the case of the Collor government - had reflected some of the demands of organized interests relating to house-building and housing finance. Cardoso's proposals followed the same principles of its predecessors. The SNH team, under Collor, had put forward a number of new ideas, some of which very consistent (VALENÇA, BONATES, 2010, p. 168).

O Programa Habitar Brasil BID, firmado em 1999 pelo Governo Federal, numa parceria com a Caixa Econômica Federal e com o Banco Interamericano de Desenvolvimento (BID), tinha por objetivo conceder recursos aos municípios para amenizarem a situação de precariedade das moradias. Assim, os projetos tornar-se-iam mais locais e pontuais, dando aos municípios maior autonomia para resolverem seus problemas de moradia.

Para Pequeno (2008),
A aprovação do Estatuto das Cidades, em 2001, e a criação do Ministério das Cidades, em 2003 trazem novos elementos para o debate. Instrumentos de regularização fundiária, mecanismos de combate à especulação imobiliária, procedimentos participativos no planejamento e na gestão da cidade legalmente constituídos passam a ser difundidos. Simultaneamente as cidades são presenteadas com um ministério específico, responsável pela formulação de uma política nacional de desenvolvimento urbano, o qual teve a compreensão de que as necessidades de desenvolvimento institucional eram pertinentes não apenas às diferentes esferas de governo, como aos demais setores envolvidos (PEQUENO, 2008, p. 7).

A partir de 2003, no governo de Luis Inácio Lula da Silva, com a criação do Ministério das Cidades, a política habitacional brasileira passou por um novo arranjo 
institucional. Seu principal foco de atuação é a inclusão dos setores excluídos do direito à cidade, já que a habitação e o acesso aos serviços básicos são fundamentais para a cidadania.

A Política Nacional de Habitação (PNH), aprovada em 2004 pelo Conselho das Cidades, propõe a criação do Sistema Nacional de Habitação (SNH), sendo o planejamento habitacional um dos componentes mais importantes. Assim, formulou-se uma estratégia para diminuir o problema habitacional no país, elaborando planos habitacionais nacional, estaduais e municipais, dimensionando o déficit habitacional, as metas a serem atingida e o necessário para alcançá-las.

Desde 2004, percebe-se uma elevação dos recursos destinados à produção habitacional de baixa renda. Os recursos do FGTS crescem assim como os recursos de origem orçamentária (Bonduki, 2008). De acordo com o Ministério das Cidades, entre os anos de 2003 a 2006, cerca de 30 bilhões de reais foram gastos em habitação social (Valença;Bonates, 2010, p. 170).

A partir de 2005, elevaram-se os investimentos para o financiamento habitacional, o foco se direcionou para a população de baixa renda. Essas mudanças foram uma resposta às reivindicações de vários setores que lutavam pela priorização de investimentos nas políticas sociais. E, em 2007, foi anunciada pelo Governo Federal a implantação do Programa de Aceleração do Crescimento (PAC), que traz investimentos em várias áreas como a infraestrutura, os setores de habitação e saneamento e a urbanização de assentamentos precários.

Confirmando, Valença;Bonates(2010) acrescenta

As the mark of Lula's second term, a so-called Acceleration Growth Program (Programa de Aceleração do Crescimento - PAC) was launched in 2007. This includes huge amounts of investments, some of which making use of FGTS money - the so-called FI-FGTS -, to be allocated to (heavy) infra-structure projects of three sorts: logistics infra-structure (including roads and train systems, ports, airports, river transport); energy infrastructure (including electricity generation and distribution, petroleum and natural gas, renewable energies); and social and urban infra-structure (including provision of urban energy, sanitation, water supply, housing and metro systems) (VALENÇA; BONATES, 2010, p. 172).

No ano de 2009, o governo Lula lançou o programa Minha Casa, Minha Vida, cuja intenção era construir um milhão de moradias. Pretendia-se com o programa promover o crescimento econômico do país, para enfrentar a crise econômica mundial desencadeada pelos Estados Unidos. Porém o programa recebeu diversas críticas devido à sua forma de operação

Geo UERJ - Ano 15, no. 24, v. 1, $1^{\circ}$ semestre de 2013 p. 125-144

ISSN: 1415-7543E-ISSN: 1981-9021

http://www.e-publicacoes.uerj.br/index.php/geouerj 
e por estar fora do Sistema/ Fundo Nacional de Habitação de Interesse Social (SNHIS/ FNHIS), que promove o controle e participação social (Valença; Bonates, 2010).

$\mathrm{Na}$ figura 01, pode-se visualizar um resumo das políticas habitacionais implantadas no Brasil, suas fontes de financiamentos,os governos em que foram criadas e em que atuaram.

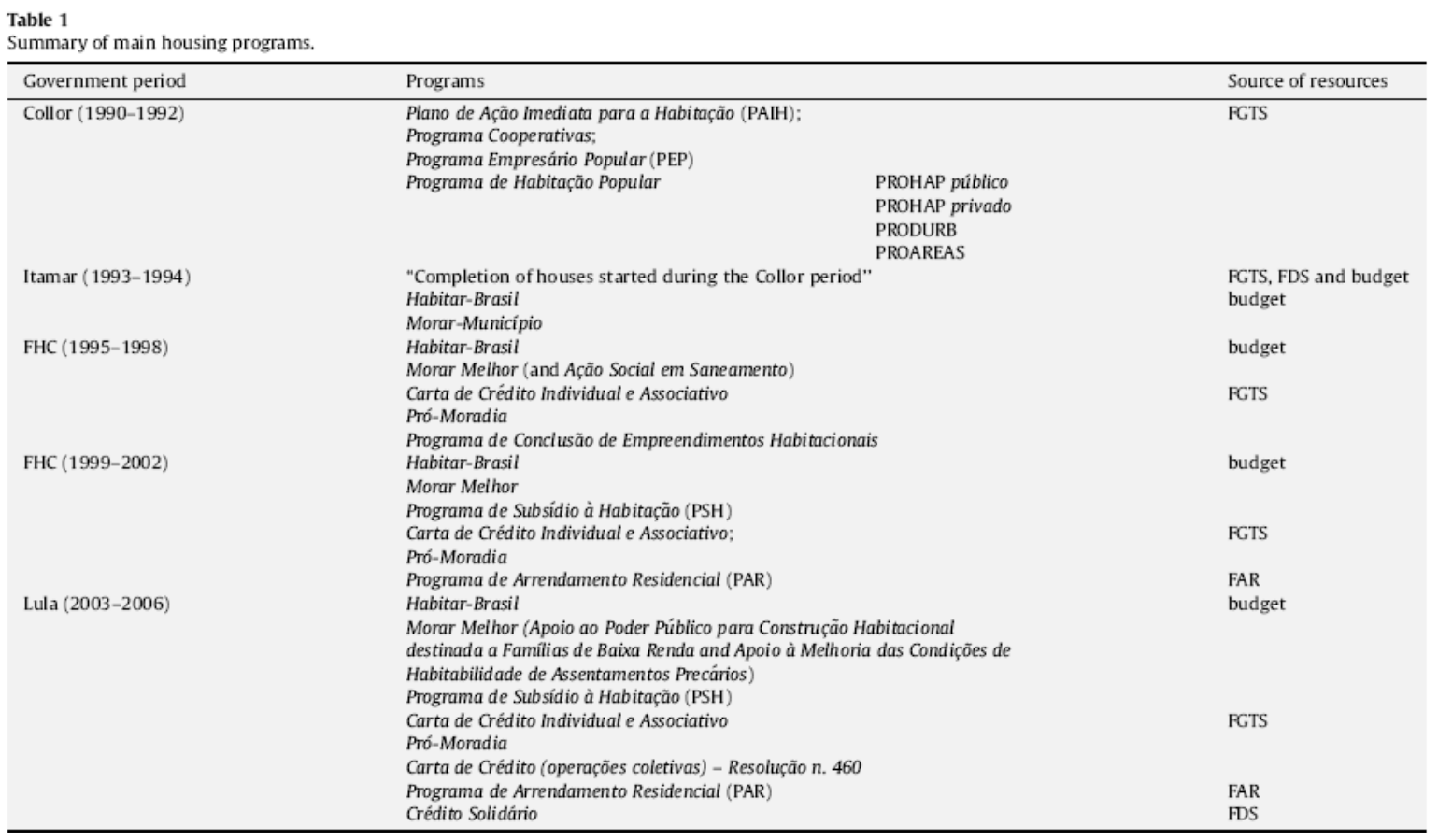

Figura 01 - Resumo das políticas habitacionais brasileiras Fonte: Valença, Bonates, 2010, p. 171

Desse modo, podemos perceber que o Brasil possui muitas marcas do período prérepublicano, onde a sociedade era patrimonialista e clientelista. E, assim, o Estado se constitui como importante produtor e consumidor do espaço, diante de investimentos e implementação de infraestrutura, financiamento de habitações e ainda, regulamentação do espaço urbano. Porém, essa atuação, muitas vezes, acaba beneficiando as classes mais favorecidas.

Como exemplo, vemos a implantação de conjuntos habitacionais em áreas periféricas, sem a infraestrutura adequada, apenas para cumprir com a "obrigação" da construção de moradias. A necessidade de infraestrutura básica como fornecimento de energia elétrica, água, recolhimento de lixo e esgoto, linhas de transporte público, além de equipamentos básicos de saúde, educação, são implementados aos poucos e a partir da pressão e reivindicações que a população exerce sobre o poder público.

Assim, Scheffer (2006) complementa que

A política habitacional, como uma política social, deve estar adequada ao planejamento urbano. Pressupõe-se que as leis provenientes do planejamento

Geo UERJ - Ano 15, no. 24, v. 1, $1^{\circ}$ semestre de 2013 p. 125-144

ISSN: 1415-7543E-ISSN: 1981-9021

http://www.e-publicacoes.uerj.br/index.php/geouerj 
urbano tenham a finalidade de proteger a organização social da cidade, com fins de manter a eficiência e a estabilidade desta, embora não podemos desconsiderar que mesmo o planejamento urbano é um espaço de conflitos de interesses. Porém, a forma espacial da cidade é mutável e em contínuo processo de renovação e recriação e o planejamento urbano interage com esta dinâmica. Assim, o problema habitacional não é um fenômeno isolado, pelo contrário, faz parte dos processos sociais, econômicos e políticos (SCHEFFER, 2006, p.277).

\section{O Problema Habitacional no Chile}

O Chile apresenta uma política habitacional interessante e que foi utilizada como referência, a partir dos anos de 1990, por outros países da América Latina, na tentativa de amenizar o déficit habitacional. A reforma política ocorrida na década de 1980 teve o apoio financeiro de instituições como o Banco Mundial e o Banco Interamericano de Desenvolvimento (BID).

Conforme Rosa; Esteves; Abyko (2006, p. 11), “A maioria da população chilena concentra-se nas cidades, sendo o Chile um dos países com maior grau de urbanização da América Latina”. Assim, juntamente com a urbanização, são gerados muitos problemas urbanos e a questão habitacional entra em foco.

A política habitacional chilena inicia sua atuação durante o século XIX e ao longo dos anos é transformada e influenciada por mudanças políticas. Com o aumento das exportações ocorrido na metade do século XIX, o país passa por um forte crescimento urbano e a população que migrava para as cidades encontrava abrigo em cortiços, casas de aluguel, galpões. Com o rápido crescimento urbano e as péssimas condições de moradia, o problema habitacional se tornou relevante na política chilena.

Nos anos de 1930 são criados no país o Departamento de Habitação, a Junta Central de Habitação e a Lei Geral sobre Construções e Urbanização. Com a criação desses órgãos, constróem-se mecanismos de financiamento para a gestão habitacional e, em 1936, com a criação da Caixa de Habitação Popular é permitida a construção de moradias para o Estado e a concessão de empréstimos ao setor privado (Rosa; Esteves; Abyko, 2006).

Entre os anos de 1941 e 1958 eram construídas, em média, 5 mil habitações por ano em todo o país. E, somente no final da década de 1950 o Chile apresenta uma política habitacional consistente. Em 1959, é lançado o Sistema de Poupança e Empréstimos (SINAP) para o financiamento habitacional. O novo sistema implantou a correção monetária para 
transações a longo prazo. Os programas habitacionais eram subisidiados e implementados pelo poder público (Rosa; Esteves; Abyko, 2006).

O SINAP auxiliou no aumento significativo da produção habitacional, que passou para 33 mil unidades anuais, até início dos anos de 1970, quando o sistema perde forças (Rosa; Esteves; Abyko, 2006).

Durante o período do Presidente Ibañez, entre os anos de 1952 e 1958, começam as discussões sobre a criação de Planos Nacionais de Habitação. Nessa época, o déficit habitacional era de aproximadamente 156 mil habitações (Rosa; Esteves; Abyko, 2006).

Nos anos de 1960, o governo tenta aliar os setores público e privado em programas financeiros, para amenizar o problema habitacional. Assim, é criado o Ministério da Habitação e Urbanismo (MINVU) com o objetivo de organizar as políticas habitacionais e administrar os fundos públicos.

Segundo Posner (2012)

Indeed, the Ministry of Housing and Urbanization states as one of its explicit goals the promotion of social cohesion, which it indicates involves 'the achievement of a peaceful coexistence and development of solidarity, shared sense of identity, belonging and collective responsibility among citizens, and the participative democratization of the processes of urban planning and decision-making' (MINVU, 2009: 30; author's translation) (POSNER, 2012, P. 51).

Em 1973, após o golpe militar, assume o poder o General Augusto Pinochet. Durante o regime militar, a política de bem-estar social e de habitação foram reestruturadas de acordo com os princípios de mercado (Posner, 2012). Além disso, as ocupações irregulares eram reprimidas pelo governo.

Em 1976, foi realizado um estudo pela Universidade do Chile, analisando a situação habitacional do país. Então, a partir de 1977, inicia-se uma reforma no setor habitacional chileno, baseada em ideias neoliberais. Desse modo, a construção e o financiamento das habitações ficaria sob o controle do setor privado e o Estado seria apenas o facilitador. O Estado atuaria como subsidiador, ajudando as famílias mais necessitadas, ou seja, seu poder aquisitivo seria complementado com subsídios diretos, e além disso, "os bancos privados ofereceriam financiamento suplementar" (Rosa; Esteves; Abyko, 2006, p. 30).

As reformas no sistema financeiro habitacional tentavam criar um mercado de crédito capaz de gerar instrumentos e recursos financeiros que intermediassem a demanda e oferta de 
financiamento imobiliário. As reformas ocorreram sobre dois elementos principais: a política de crédito e de subsídios.

Segundo Rosa; Esteves; Abyko(2006),

Desde 1983 o governo tem financiado um Programa de Erradição de Assentamentos irregulares executados nos municípios com financiamento parcial do Banco Interamericano de Desenvolvimento (BID). O objetivo desse programa é a erradição por completo dos assentamentos irregulares (Rosa; Esteves; Abyko, 2006, p. 29).

Durante a transição para a democracia, a partir de 1990, os gastos com investimentos sociais aumentaram significativamente (Posner, 2012). E, em 2001, os investimentos habitacionais chegaram a US\$ 9,2 bilhões ou 14\% do PIB (Rosa; Esteves; Abyko,2006).

A política habitacional chilena serviu e ainda serve de exemplo para outros países em desenvolvimento, porém o modelo sofre algumas críticas. As principais são a falta de qualidade urbanística e construtiva dos conjuntos habitacionais e sua inserção em áreas periféricas, afastadas dos centros urbanos, sem infraestrutura, já que há a necessidade de terrenos baratos para sua construção.

\section{Considerações Finais}

Assim, fazendo um comparativo entre a situação habitacional no Chile e no Brasil, vemos que o Chile é um dos países mais urbanizados da América Latina e já possui políticas no âmbito habitacional desde o século XIX. Na década de 1930, o país já possui um Departamento de Habitação, para tratar do financiamento habitacional e em 1936 é criada a Caixa de Habitação Popular. Enquanto isso, no Brasil, o problema habitacional era tratado por particulares, não pelo Estado e na década de 1930 são inaugurados os primeiros Institutos de Aposentadoria e Pensões (IAPs), para abrigar os próprios funcionários dos Institutos e não necessariamente a população necessitada. Além disso, somente no ano de 1946 que foi criada a Fundação da Casa Popular (FCP), que tinha como objetivo solucionar o problema habitacional brasileiro.

No Chile, entre os anos de 1941 e 1958 eram produzidas em torno de 5 mil habitações por ano e, já no início da década de 1950, contava com uma política habitacional consistente. Em 1958 foi criado o SINAP, que auxiliou na implantação de políticas habitacionais e se registrou até o ano de 1970, 33 mil moradias financiadas por ano. 
No Brasil, somente com a Ditatura Militar, que iniciou em 1964, é que o país passou a ter uma política habitacional consistente, através da criação do BNH e SFH. Assim, entre os anos de 1964 e 1986, tempo de duração do BNH, o SFH financiou aproximadamente 2,4 milhões de moradias para a população de baixa renda. O país contava com recursos do FGTS para o financiamento dessas moradias.

Quando em 1973 foi instalada a Ditadura no Chile, a política habitacional do país passa por várias mudanças, assim como o Brasil. A diferença é que no Chile o Estado passa a dar apenas subsídio para a construção das moradias e quem tem o controle é o setor privado, que constrói e vende as habitações.

No Brasil, entre os anos de 1970 e 1992, quando ocorrem reformas no sistema financeiro habitacional, o país observa uma redução do déficit de moradias. O SFH chegou a conceder créditos para mais de 600 mil famílias em um único ano. Porém, no período entre 1992 e 2003, quando a política habitacional enfrentava uma grave crise, financiou apenas cerca de 128 mil moradias. Entre os anos de 1991 e 2001 o país apresentou um aumento de $11 \%$ no déficit habitacional absoluto.

No Chile , em 1992, 17,8\% da população moravam em condições de déficit e em 2002 esse número atingia apenas $9,9 \%$ da população. A diminuição das habitações deficitárias ocorreu devido ao grande "crescimento econômico do Chile" e à "expansão do crédito imobiliário propiciada pelas reformas do sistema de financiamento habitacional" (ROSA; ESTEVES; ABYKO, 2006, p.15).

Quanto a questão de investimentos em infraestrutura, o Chile, em 2002, conseguiu atender aproximadamente $90 \%$ dos domicílios com água potável e esgotamento sanitário.

No caso brasileiro, o abastecimento de água e sistema de esgoto que, em 1970 atendiaaproximadamente $16 \%$ da população passa a atender em torno de $70 \%$ dos domicílios em 2001.

Assim, percebe-se uma maior atenção do poder público chileno nas questões habitacionais e de saneamento. O Chile apresenta uma política habitacional mais consistente que o Brasil, porém ambos precisam ver em suas políticas adaptações, tendo em vista as mudanças na realidade da população de baixa renda. Além do mais, a política habitacional, não somente no Brasil e Chile, mas a implementada em todos os países da América Latina sofre fortes críticas por ter baixa qualidade de planejamento e urbanística, os conjuntos 
também possuem baixa qualidade construtiva e são implementados em áreas distantes, geralmente na periferia, onde os terrenos são mais baratos.

\section{Referências}

BOTEGA, Leonardo da Rocha. De Vargas a Collor: urbanização e política habitacional no Brasil. Revista Espaço Plural. Ano VIII, n. 17, p. 65 -72, 2º semestre 2007.

BONDUKI, Nabil. Origens da Habitação Social no Brasil. 4. ed. São Paulo: Estação Liberdade, 2004.

CARDOSO, Adauto Lucio; ABIKO, Alex Kenia. Procedimentos de Gestão Habitacional para População de Baixa Renda. Porto Alegre: ANTAC, 2006(Coleção Habitare, v. 5)

CARDOSO, Adauto Lucio. Habitação Social nas Metrópoles Brasileiras. Uma Avaliação das Políticas Habitacionais em Belém, Belo Horizonte, Porto Alegre, Recife, Rio de Janeiro e São Paulo no final do século XX. Porto Alegre: ANTAC, 2007.

EARLE, Lucy. From Insurgent to Transgressive Citizenship: Housing, Social Movements and the Politics of Rights in São Paulo. JournalofLatin American Studies, v. 44, p. 97-126, 2012.

FERNANDES, Edesio. Consideracionesgenerales sobre las politicas publicas de regularizacion de asentamientosinformalesenAmerica Latina. Eure, v. 34, n. 102, p. 25-38, agosto 2008.

GOMES, Rita de Cássia da Conceição; SILVA, Anieres Barbosa da; SILVA, Valdenildo Pedro da.Política habitacional e urbanização no Brasil. Scripta Nova, v. 7, n. 146(083), 1 de agosto de 2003.

MARICATO, Ermínia. Urbanismo na periferia do mundo globalizado. São Paulo em Perspectiva, v. 14, n. 4, p. 21-33, 2000.

PEQUENO, Renato. Políticas habitacionais, favelização e desigualdades socioespaciais nas cidades brasileiras: transformações e tendências. Scripta Nova, v. 12, n. 270(35), 1 de agosto de 2008.

POSNER, Paul W. Targeted Assistance and Social Capital: Housing Policy in Chile's Neoliberal Democracy. 2012.International Journal of Urban and Regional Research, v. 36, n.1, p. 49-70, 2012.

RAMÍREZ, Ronaldo. Evaluación social de políticas y programas de vivienda: um análisis de lacontribución de lavivienda a laredución de la pobreza urbana. Boletíndel Instituto de laVivienda, Chile, v. 17, n. 045, p. 9-57, 2002.

ROSA, Alba Maria; Esteves, Antônio César; ABYKO, Alex Kenya. Gestão Habitacional no Chile. São Paulo, 2006. Disponível em: <http://pcc5839.pcc.usp.br/Textos_Tecnicos/GestaoHabitacionalChileJunho2006.pdf> Acesso em 20 jul. 2012.

Geo UERJ - Ano 15, no. 24, v. 1, $1^{\circ}$ semestre de 2013 p. 125-144

ISSN: 1415-7543E-ISSN: 1981-9021

http://www.e-publicacoes.uerj.br/index.php/geouerj 
SCHEFFER, Sandra Maria. Espaço urbano e política habitacional: uma análise sobre Ponta Grossa, Emancipação, v.6, n. 1, p. 257-278, 2006.

SERRANO, Julián Salas. Latinoamérica: Hambre de vivienda. Boletíndel Instituto de laVivienda, Chile, v. 17, n. 045, p. 58-69, 2002.

VALENÇA, Márcio Moraes; BONATES, Mariana Fialho. The trajectory of social housing policy in Brazil: From the National Housing Bank to the Ministry of the Cities. Habitat Internacional, v. 34, p. 165-173, 2010.

Artigo recebido para publicação em janeiro de 2013.

Artigo aceito para publicação em junho de 2013. 